\title{
Removal of copper ions from aqueous solution using silica derived from rice straw: comparison with activated charcoal
}

\author{
G. Sharaf $\cdot$ H. Hassan
}

Received: 26 January 2013/Revised: 6 April 2013/Accepted: 26 May 2013/Published online: 3 July 2013

(C) Islamic Azad University (IAU) 2013

\begin{abstract}
The batch removal of copper(II) ions from aqueous solution under different experimental conditions using alkali-leached silica and activated charcoal was investigated in this study. The copper(II) uptake was dependent on varying time, $\mathrm{pH}$, copper concentration and temperature. Copper sorption was found fast reaching equilibrium within $1 \mathrm{~h}$ with better performance for alkalileached silica than charcoal. Copper sorption was low at low $\mathrm{pH}$ values and increased with rise in initial $\mathrm{pH}$-value until 6.7. Sorption fits well the Langmuir and Freundlich equations with higher uptake by increasing temperature. According to Langmuir equation, the maximum uptake of $\mathrm{Cu}(\mathrm{II})$ ions by alkali-leached $\mathrm{SiO}_{2}$ and charcoal was found to be 242.5 and $94.4 \mathrm{mmol} / \mathrm{g}$ at temperature $60{ }^{\circ} \mathrm{C}$ and $\mathrm{pH}$. Thermodynamic studies confirm that the process was spontaneous and endothermic nature. Kinetic data for $\mathrm{Cu}$ (II) sorption was found to follow pseudo-second-order model.
\end{abstract}

Keywords Removal - Copper - Alkali-leached silica . Activated charcoal

\section{Introduction}

Heavy metals are groups of pollutants in the environment because of their toxicity and non-biodegradable behavior which are tend to accumulate in living organisms (Kobya et al. 2005) and represent a threat to human life and

G. Sharaf $(\bowtie) \cdot$ H. Hassan

Hot Laboratories Center, Atomic Energy Authority,

Cairo 13759, Egypt

e-mail: gehansha@yahoo.com environment. Some of the trace elements play essential roles in biological processes, but at higher concentration, they may be toxic to the biota, and they disturb the biochemical processes and cause health hazards (Kazemipour et al. 2008; Arivoli et al. 2008). Therefore, the removal of heavy metals is necessary before effluents depositions entering into environment. Copper metal arises from the industries of copper mining and smelting, brass and bronze manufacturing, electroplating industries and excessive use of copperbased agrochemicals (Madhava Rao et al. 2006). The presence of $\mathrm{Cu}(\mathrm{II})$ ions causes serious toxicological concerns; it is usually known to deposit in brain, skin, liver, pancreas and myocardium (Davis et al. 2000), continued inhalation of copper-containing sprays is linked with an increase in lung cancer among exposed workers (Davis et al. 2003).

Conventional techniques for removing dissolved heavy metals include chemical precipitation, carbon sorption, electrolytic recovery, ion-exchange, solvent extraction or liquid membrane separation (Vasuderan et al. 2003; Gõksungur et al. 2005; Júnior et al. 2003; Lodeiro et al. 2005; Liu et al. 2006; Sharma et al. 2006). These techniques are sometimes restricted because of technical or economic constraints as a result of high capital and operational cost. An alternative approach to this technique is sorption process, which offers potential advantages such as low operating cost, minimization of the volume of the chemical and the sludge to be disposed off.

Rice is the world's second largest cereal crop after wheat but produces the largest amount of crop residues, which is removed during the harvesting of rice. In Egypt, the amount of rice straw discarded annually is about 3 million tons (Bakker et al. 2009; Zaky et al. 2008). The government installed 2 units for converting limited amount of rice straw into gas to be used as fuel. The disadvantage of this process is accumulation of residue, which is semi-burned rice straw 
ash. Yet, this residue, which is rich in silica, has no commercial utilization (Zaky et al. 2008). Also, rice straw is low in digestibility and protein to be used as animal fodder. Rice straw was selected since it is available in huge quantity as a waste and has limited commercial interest. It has low a cost and contain about $15-22 \% \mathrm{SiO}_{2}$ in hydrated amorphous form like silica gel (Van Soest 2006), which is one of the good adsorbents. Therefore, it is of ecological and economical point of view to explore an advantage of utilization of $\mathrm{SiO}_{2}$ produced from rice straw.

The objective of this work was to study the feasibility of using alkali-leached $\mathrm{SiO}_{2}$ and activated charcoal as adsorbents for the removal of $\mathrm{Cu}(\mathrm{II})$ from waste water. In this work, batch experiments were carried out to evaluate the sorption characteristics of the alkali-leached $\mathrm{SiO}_{2}$ and activated charcoal for $\mathrm{Cu}$ (II) removal from aqueous solutions. The sorption isotherms, thermodynamic parameters, kinetics and $\mathrm{pH}$ effect were examined.

\section{Materials and methods}

\section{Sorbent preparation}

The precursor rice straw was stirred in $5 \% \mathrm{KOH}$ at a weight ratio $1: 12$ of rice straw to solution and heated to boiling for $30 \mathrm{~min}$.; then, the mixture was left overnight, filtered and washed twice with distilled water until filtrate become neutral. Potassium hydroxide reacts with silica according to the following reaction:

$\mathrm{SiO}_{2}+2 \mathrm{KOH} \rightarrow \mathrm{K}_{2} \mathrm{SiO}_{3}+\mathrm{H}_{2} \mathrm{O}$

The alkali-silica reaction mechanism was described using different models (Den classer and Kataoka 1981; Pool 1992; Wang and Gillott 1991; Dron 1990; Bulteel et al. 2002). Silica dissolution is controlled by the hydroxide diffusivity in reactive grains and by hydroxide absorption on the solid surface. The hydroxide diffusivity increases with the $\mathrm{pH}$ and ionic strength of the solution (Chatterji et al. 2000). So, the method of preparation of $\mathrm{SiO}_{2}$ was operated with $5 \% \mathrm{KOH}$, which the $\mathrm{pH}$ of solution raises to 13 , and high hydroxide diffusivity reached with suitable amount of leached silica was obtained.

The filtrate was collected, and subsequently used, as it is predicted to contain leached silica the major component of the ash. To the filtrate, $10 \% \mathrm{HCl}$ was added so as to precipitate dissolved silica, until the $\mathrm{pH}$ reached (5-7). White-gray precipitate was formed, which were filtrated and dried at $110{ }^{\circ} \mathrm{C}$.

\section{Chemicals and equipment}

All the chemicals used were of analytical grade. Stock solution of $\mathrm{Cu}(\mathrm{II})(15.74 \mathrm{mmol} / \mathrm{l})$ was prepared in deionized water using $\mathrm{Cu}$ (II) sulfate pentahydrate, $\mathrm{CuSO}_{4} \cdot 5 \mathrm{H}_{2} \mathrm{O}$. The solution of different dilutions (0.393-3.934 mmol/l) required for the sorption studies were prepared by dilution of stock solutions. Water used in all experiment has quality deionized water. Activated charcoal was purchased from Sigma-Aldrich Company. The $\mathrm{pH}$ measurements were carried out using a Model G820 pH meter, West Germany. The metal concentrations in the samples were determined using atomic absorption spectroscopy (Hitachi Z-8100, Germany). Thermal analysis measurements were carried out using Du Pont analyzer Model 9900. The infrared spectra were obtained as KBr pellets ( $1 \mathrm{wt} \%$ ) and the equipment used was a Shimadzu FT-IR 33,000 spectrophotometer with $4 \mathrm{~cm}^{-1}$ resolution, using 200 cumulative scans.

Characterization of the studied sorbents

\section{Measurement of sorbent $\mathrm{pH}$}

$1.0 \mathrm{~g}$ of the activated charcoal or $\mathrm{SiO}_{2}$ (prepared from rice straw) mixed with $50 \mathrm{ml}$. doubly distilled water was shaken for $30 \mathrm{~min}$ at $100{ }^{\circ} \mathrm{C}$. After cooling to room temperature $\left(\sim 25^{\circ} \mathrm{C}\right)$, the $\mathrm{pH}$ of the filtrate was measured accurately with an error of \pm 0.01 .

\section{Thermal analysis (TGA and DTA)}

Thermal analysis measurements were carried out using Du Pont analyzer Model 9900. A known amount of sample was taken in crucible and its dehydration/combustion was carried out from room temperature to $700{ }^{\circ} \mathrm{C}$ for charcoal and $800{ }^{\circ} \mathrm{C}$ for $\mathrm{SiO}_{2}$ powder at a heating rate $20{ }^{\circ} \mathrm{C} / \mathrm{min}$. The experiment was performed in static air.

\section{Fourier transform infrared spectroscopy (FTIR spectra)}

The infrared spectra were obtained as $\mathrm{KBr}$ pellets (1 wt $\%$ ) and the equipment used was a Shimadzu FT-IR 33000 spectrophotometer with $4 \mathrm{~cm}^{-1}$ resolution, using 200 cumulative scans.

\section{Ash content}

Ash is the inorganic combustion residue remaining after the water and organic matter have been removed by heating in the presence of oxidizing agents, which provides a measure of the total amount of minerals within a sample. The crucibles are placed in the furnace at $900{ }^{\circ} \mathrm{C} / 1 \mathrm{~h}$ and the door is closed. The next day, the crucibles are removed from the furnace and allowed to cool in a desiccator before the crucible and contents are weighed. The ash content is quoted as a percentage of the original sorbent. \% $\mathrm{Ash}=[(\mathrm{wt}$ of ash/wt of sorbent $) \times 100]$. 
Batch sorption studies

Batch sorption studies were carried out by shaking $0.25 \mathrm{~g}$ of the sorbent with $25 \mathrm{ml}$ of the aqueous solutions of $\mathrm{Cu}$ (II) ion in different conical flask at $150 \mathrm{rpm}$. All metal solutions were used at neutral $\mathrm{pH}$ and performed at room temperature unless otherwise stated. The effect of $\mathrm{pH}$ of the initial solution on the equilibrium uptake of $\mathrm{Cu}$ (II) ions was analyzed over a $\mathrm{pH}$ range from 2.0 to 9.0 . The $\mathrm{pH}$ was adjusted using $0.1 \mathrm{M} \mathrm{NaOH}$ and $0.1 \mathrm{M} \mathrm{HCl}$ solutions. The sorption experiments were also conducted to determine the equilibrium time, the optimum $\mathrm{pH}$ and dosage of the adsorbent for maximum sorption.

The amount of $\mathrm{Cu}^{2+}$ adsorbed by the adsorbent and the percentage removal of $\mathrm{Cu}^{2+}$ are calculated using the following Eqs. (1) and (2), respectively.

$q_{t}=\left(C_{0}-C_{t}\right) V / W$

$\%$ Removal of $\mathrm{Cu}(\mathrm{II})=\left(\left(C_{0}-C_{t}\right) / C_{0}\right) 100$

where, $q_{t}$ is the sorption capacity in $\mathrm{mmol} / \mathrm{g}, C_{0}$ is the initial concentration of metal ion $(\mathrm{mmol} / \mathrm{l})$ and $C_{t}$ is the concentration of $\mathrm{Cu}(\mathrm{II})$ at time $(t)$ in $\mathrm{mmol} / \mathrm{l} . V$ is the volume solution of $\mathrm{Cu}^{2+}(\mathrm{ml})$, and $W$ is the total amount of adsorbent (g).

\section{Sorption kinetics}

The sorption process in terms of the order and the rate constant can be evaluated using the kinetic sorption data. The process of $\mathrm{Cu}^{2+}$ removal from an aqueous phase by any adsorbent can be explained by using kinetic models and examining the rate-controlling mechanism of the sorption process such as chemical reaction, diffusion control and mass transfer. The kinetic parameters are useful in predicting the sorption rate which can be used as important information in designing and modeling of the sorption operation. The kinetics of removal of $\mathrm{Cu}(\mathrm{II})$ is explicitly explained in the literature using pseudo-first-order and pseudo-second-order.

\section{Pseudo-first-order kinetics}

Lagergren (1898) showed that the rate of sorption of solute on the adsorbent is based on the sorption capacity and followed a pseudo-first-order equation. The non-linear form of the pseudo-first-order equation is given by Eq. (3):

$\mathrm{d} q_{t} / \mathrm{d}_{t}=k_{\mathrm{ad}}\left(q_{e}-q_{t}\right)$

where, $q_{e}$ and $q_{t}$ are the amounts of $\mathrm{Cu}$ (II) adsorbed ( $\mathrm{mmol} / \mathrm{g}$ ) at equilibrium time and at any instant of time, $t$, respectively, and $k_{\text {ad }}(1 / \mathrm{min})$ is the rate constant of the pseudo-first-order sorption operation. The integrated rate law after application of the initial condition of $q_{t}=0$ at $t=0$ becomes a linear equation as given by Eq. (4):

$\log \left(q_{e}-q_{t}\right)=\log q_{e}-\left(k_{\mathrm{ad}} / 2.303\right) t$

The plot of $\log \left(q_{\mathrm{e}}-q_{t}\right)$ versus $t$ gives a straight line for the pseudo-first-order sorption kinetics, from the slope of respective plot, the sorption rate constant, $k_{\mathrm{ad}}$, is estimated. Pseudo-first-order kinetic equation differs from true firstorder equation in two ways: (1) the parameter $k_{\mathrm{ad}}\left(q_{\mathrm{e}}-q_{t}\right)$ does not represent the number of available sites, and (2) the parameter $\log \left(q_{\mathrm{e}}\right)$ is an adjustable parameter and often it is found that it is not equal to the intercept of the plot of $\log \left(q_{\mathrm{e}}-q_{t}\right)$ versus $t$. Hence, pseudo-first-order kinetic model (Eq. 3) is used for estimating $k_{\mathrm{ad}}$ alone, which is considered as mass transfer coefficient in the design calculations.

\section{Pseudo-second-order kinetics}

As pseudo-first-order kinetic model gives only $k_{\mathrm{ad}}$ and $q_{\mathrm{e}}$ cannot be estimated using this model, applicability of the second-order kinetics Ho et al. (2000) has to be tested for the estimation of $q_{\mathrm{e}}$ with the rate equation given by Eq. (5):

$\left(\mathrm{d} q_{t} / \mathrm{d}_{t}\right)=k_{2}\left(q_{e}-q_{t}\right)^{2}$

where $k_{2}(\mathrm{~g} / \mathrm{mmol} \mathrm{min})$ is the second-order rate constant. From the boundary conditions, $t=0$ to $t$ and $q_{t}=0$ to $q_{t}$, the integrated form of the equation becomes Eq. (6):

$\left(1 /\left(q_{e}-q_{t}\right)=\left(1 / q_{e}\right)+k_{2} t\right.$

Eq. (6) can be written in a linear form, as given by Eq. (7):

$\left(t / q_{t}\right)=(1 / h)+\left(1 / q_{e}\right) t$

where $h=k_{2} q_{\mathrm{e}}^{2}$ that can be regarded as the initial sorption rate as $t \rightarrow 0$. Under such circumstances, the plot of $t / q_{t}$ versus $t$ should give a linear relationship, which allows the computation of $q_{\mathrm{e}}$ and $k_{2}$.

\section{Sorption isotherms}

The equilibrium between an adsorbate immobilized on the active sites of an adsorbent and the adsorbate remaining in aqueous phase is usually presented by sorption isotherms. In order to describe the sorption characteristics of the studied sorbents used in water and wastewater treatment, experimental equilibrium data are most frequently modeled by the relationships developed by Freundlich and Langmuir isotherm models. Heavy metal sorption from synthetic solutions was also here tested using these relationships. 
Freundlich isotherm model

Freundlich equation is derived to model the multilayer sorption and for the sorption onto heterogeneous surfaces. The logarithmic form of Freundlich equation may be written as (Eq. 8):

$\log q_{e}=\log K_{f}+(1 / n) \log C_{e}$

where $q_{e}$ is the amount of metal ion sorbed per unit weight of sorbent $(\mathrm{mmol} / \mathrm{g}), C_{e}$ is the equilibrium concentration of metal ion in equilibrium solution ( $\mathrm{mmol} / \mathrm{l}), K_{f}$ is a constant indicative of the relative sorption capacity of the adsorbent $(\mathrm{mmol} / \mathrm{g}$ ), and $1 / n$ is a constant indicative of the intensity of sorption process.

\section{Langmuir isotherm model}

Langmuir sorption isotherm models the monolayer coverage of sorption surfaces and assumes that sorption occurs on a structurally homogeneous adsorbent and all the sorption sites are energetically identical. The linearized form of the Langmuir equation is given by the following formula:

$\left(C_{e} / q_{e}\right)=\left(1 /\left(Q^{0} b\right)\right)+\left(1 / Q^{0}\right) C_{e}$

where $Q^{0}$ is the monolayer sorption capacity $(\mathrm{mmol} / \mathrm{g}$ ) and $b$ is a constant related to the free energy of sorption $\left(b \propto e^{-\Delta G / R T}\right)$.

\section{Results and discussion}

\section{Characterization of sorbents}

Characteristics of alkali-leached silica and commercial activated charcoal are given in Table 1 .

The importance of the surface chemistry of the studied sorbents should not be ignored. In this work, infrared spectroscopy was used to obtain information about the chemical structure and functional groups of the prepared

Table 1 Experimental determined values of different parameters of the studied sorbents

\begin{tabular}{lll}
\hline Parameter & $\begin{array}{l}\text { Silica } \\
\text { powder }\end{array}$ & $\begin{array}{l}\text { Activated } \\
\text { charcoal }\end{array}$ \\
\hline $\mathrm{pH}$ & 3.60 & 6.70 \\
Apparent density $\left(\mathrm{g} \mathrm{cm}^{-3}\right)$ & 1.02 & 0.55 \\
Bulk density $\left(\mathrm{g} \mathrm{cm}^{-3}\right)$ & 1.27 & 0.74 \\
Specific surface area $\left(\mathrm{m}^{2} \mathrm{~g}^{-1}\right)$ & 9.50 & 393.78 \\
Mean particle size $($ diameter $)(\mu \mathrm{m})$ & 20.80 & 0.68 \\
Ash content $(\%)$ & 0.70 & 0.48 \\
Zero point charge $(\mathrm{pHzpc})$ & $1.8-2.2$ & $3.1-3.5$ \\
\hline
\end{tabular}

silica and the commercial activated charcoal (Comez-Serrano et al. 1996; Pastor-Villegas et al. 1993; Vink et al. 1994; Solum et al. 1995). The FTIR spectra of silica prepared from rice straw and the activated charcoal are shown in Fig. 1a, b. For silica powder, Fig. 1a, the broad absorption band at $3,500-3,300 \mathrm{~cm}^{-1}$ is assigned to the $\mathrm{O}-\mathrm{H}$ stretching vibrations of surface $\mathrm{OH}$ groups (Kalapathy et al. 2000) and to the gel network. This band was associated with the hygroscopic nature of silica gel that was not affected by drying at $110{ }^{\circ} \mathrm{C}$. The absorption band at $1,750-1,730 \mathrm{~cm}^{-1}$ region is characteristic of $\mathrm{C}=\mathrm{O}$ stretching vibrations. The absorption band at about $1,600 \mathrm{~cm}^{-1}$ is characteristic of $\mathrm{C}=\mathrm{C}$ stretching vibrations in aromatics ring (Silva et al. 2008). The absorptions at 1,080 and $460 \mathrm{~cm}^{-1}$ are attributed to $\mathrm{Si}-\mathrm{O}$ stretching and $\mathrm{Si}-\mathrm{O}$ bending indicating of the silica presence (Salvado and Navarro 1992; Davis and Liu 1997; Pilau et al. 2008; Kurihara et al. 2004). Band at $800-780 \mathrm{~cm}^{-1}$ region is due to (Si-O-Si stretching) and band at $480-460 \mathrm{~cm}^{-1}$ region is due to ( $\mathrm{Si}-\mathrm{O}-\mathrm{Si}$ bending) (Abou-Sekkina et al. 2010). The IR bands of alkali-leached silica are quite comparable with those reported for amorphous silica present in natural sources. This reflects that silica present in our sample is in amorphous form which is actually the most reactive form of silica (Abou-Sekkina et al. 2010).

For FTIR spectra of the commercial activated charcoal carbonized at $400{ }^{\circ} \mathrm{C}$, Fig. $1 \mathrm{~b}$, the $\mathrm{C}=\mathrm{O}$ mode at about $1,700 \mathrm{~cm}^{-1}$ and $\mathrm{C}-\mathrm{H}$ deformation vibration mode at about $1,400 \mathrm{~cm}^{-1}$ are weakly detected, $\mathrm{C}=\mathrm{C}$ aromatic mode at about $1,600 \mathrm{~cm}^{-1}$ is clearly detected. The absorption band at $1,000-1,300 \mathrm{~cm}^{-1}$ region is characteristic of stretching vibration $\mathrm{C}-\mathrm{O}$. It was assumed that, the formation of the $\mathrm{C}=\mathrm{O}$ and $\mathrm{C}=\mathrm{C}$ modes temporarily was caused by formation of $\mathrm{H}_{2} \mathrm{O}$ in a pyranose ring at the primary carbonization step because these modes does not exist in the original cellulose (Cao et al. 2013).

For thermal analysis performed on alkali-leached silica with $5 \% \mathrm{KOH}$ was investigated under temperature range from 25 to $800{ }^{\circ} \mathrm{C}$ as shown in Fig. 2a. The TG curve of silica powder dried at $110{ }^{\circ} \mathrm{C}$ exhibits three main regions, the first region with the range $50-300{ }^{\circ} \mathrm{C}$ corresponding to the removal of the moisture content of the sample (about $3.5 \%)$ together with some volatile materials. The second stage within the range $300-550{ }^{\circ} \mathrm{C}$, amounts to about $9 \%$ would corresponding to the burning of the carbonaceous material on the sample. The last region in the range $\left(550-800{ }^{\circ} \mathrm{C}\right.$ ) is of low mass loss (about $1.5 \%$ ), which may be corresponding combustion of carbon that was firmly adsorbed on the surface of the solid material (Kenawy et al. 1994). DTA-curve shows four endothermic peaks occurring at $105,160,220$ and $300{ }^{\circ} \mathrm{C}$ attributed to evaporation of moisture and removal of some volatile materials. The exothermic peak at $365{ }^{\circ} \mathrm{C}$ was corresponding to 
Fig. 1 FTIR spectra of alkalileached $\mathrm{SiO}_{2}$ from rice straw (a) and activated charcoal (b)
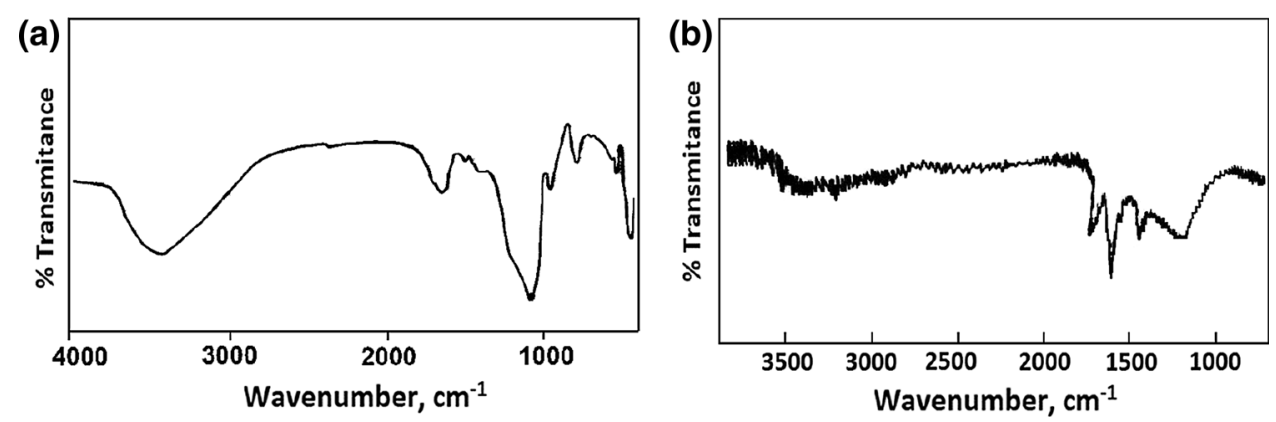

combustion of organic compounds. Small endothermic peak at $550-630 \mathrm{~cm}^{-1}$ may be due to quartz transformation (Elwan et al. 2006).

On the other side, DTA-TG curves of specimen activated charcoal dried at $150{ }^{\circ} \mathrm{C}$ were analyzed under temperature range from 25 to $700{ }^{\circ} \mathrm{C}$ and were shown in Fig. 2b. It is clear that DTA pattern shows broad exothermic peak at $405{ }^{\circ} \mathrm{C}$, which is due to burning of the residual organic materials. TG curve of charcoal sample shows two steps representing a loss in weight corresponding to $10 \mathrm{wt} \%$ due to loss of moisture at temperature lower than $125{ }^{\circ} \mathrm{C}$ and $84.5 \mathrm{wt} \%$ corresponding to decompose of charcoal and loss of volatile compounds at temperature range from 300 to $580{ }^{\circ} \mathrm{C}$. These steps extended from $25^{\circ} \mathrm{C}$ to $580{ }^{\circ} \mathrm{C}$.

\section{Effect of $\mathrm{pH}$}

The solution $\mathrm{pH}$ is one of the most important factors that control the sorption of metal ions. The effect of $\mathrm{pH}$ of the solution of $\mathrm{Cu}(\mathrm{II})$ ions by silica powder and activated charcoal was determined. The $\mathrm{pH}$ of the solution was controlled by the addition of $0.1 \mathrm{M} \mathrm{NaOH}$ and $0.1 \mathrm{M} \mathrm{HCl}$ solutions. Sorption of $\mathrm{Cu}(\mathrm{II})$ by both sorbent materials at different initial $\mathrm{pH}$ is given in Fig. 3a.

It can be observed that the removal of $\mathrm{Cu}$ (II) increases with increasing $\mathrm{pH}$, from its minimum at $\mathrm{pH} 2$ to its maximum at
$\mathrm{pH}$ 6-7. The percentage of sorption increased from $33 \%$ at $\mathrm{pH} 2$ to $90 \%$ at $\mathrm{pH} 6.7$ for silica powder and from $18 \%$ at $\mathrm{pH}$ 2 to $58 \%$ at pH 6.7 for charcoal. The $\mathrm{pH}$ of solution can affect on extend of sorption because it influences the metal chemistry in solution as well as the surface chemistry of the sorbent. The chemistry of metal ions in aqueous solution is dominated by hydrolysis and precipitation when hydroxide ions are the only significant ligand present in the aqueous system. The relative distribution of copper(II) species present in copper(II) $-\mathrm{H}_{2} \mathrm{O}$ system was shown in Fig. $3 \mathrm{~b}$.

According to Fig. $3 b$, the free aqua copper (II) ions predominate in aqueous solution in the acidic $\mathrm{pH}$ range. Hence, sorption increases sharply from the $\mathrm{pH}$ range 2 to 6.5 , which basically a reflection of the association between the predominant species of $\mathrm{Cu}^{2+}$ and the sorbent surface. This in turn means that variation in sorption density in this $\mathrm{pH}$ range is largely due to the influence of $\mathrm{pH}$ on the surface chemistry of the sorbent. At $\mathrm{pH}$ values higher than 6.5 , slightly increase of $\mathrm{Cu}^{2+}$ uptake was obtained due to starting precipitation of $\mathrm{Cu}^{2+}$ ions (see Fig. 3a).

It is well known that sorbent surface contains functional groups which can be protonated or deprotonated, depending on the $\mathrm{pH}$ of the aqueous medium. The surface charge of $\mathrm{SiO}_{2}$ and charcoal is usually characterized by a point of zero charge or $\mathrm{pHzpc}\left(\mathrm{SiO}_{2}\right)$, and $\mathrm{pHzpc}$ (charcoal). The surface charge of sorbent is positive at $\mathrm{pH}<\mathrm{pHzpc}$ and it is negative for $\mathrm{pH}>$ phzpc (Hoong and Ali 2000).
Fig. 2 DTA/TG curves for alkali-leached $\mathrm{SiO}_{2}$ (a) and for activated charcoal (b)
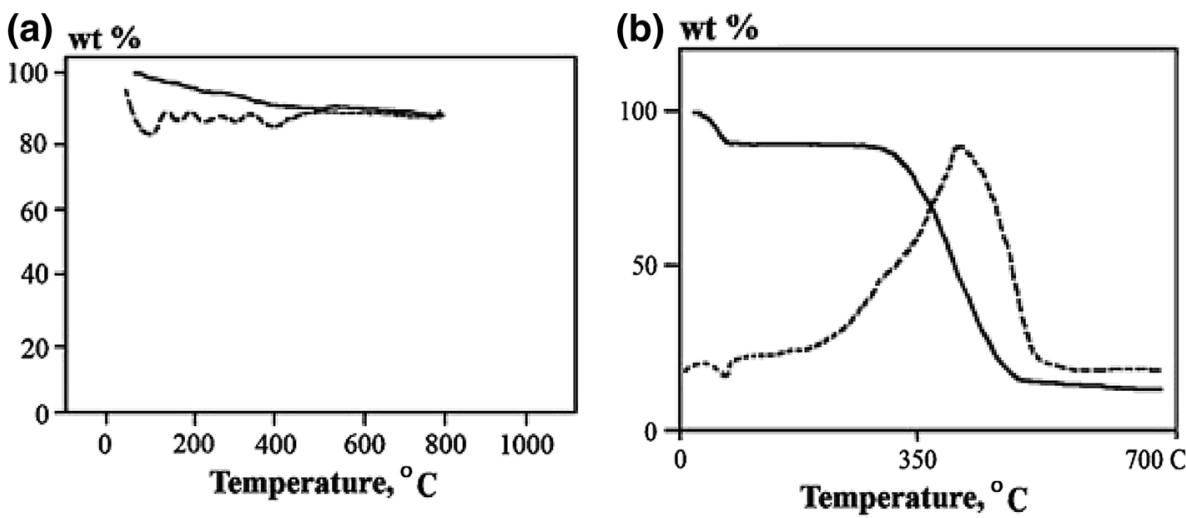

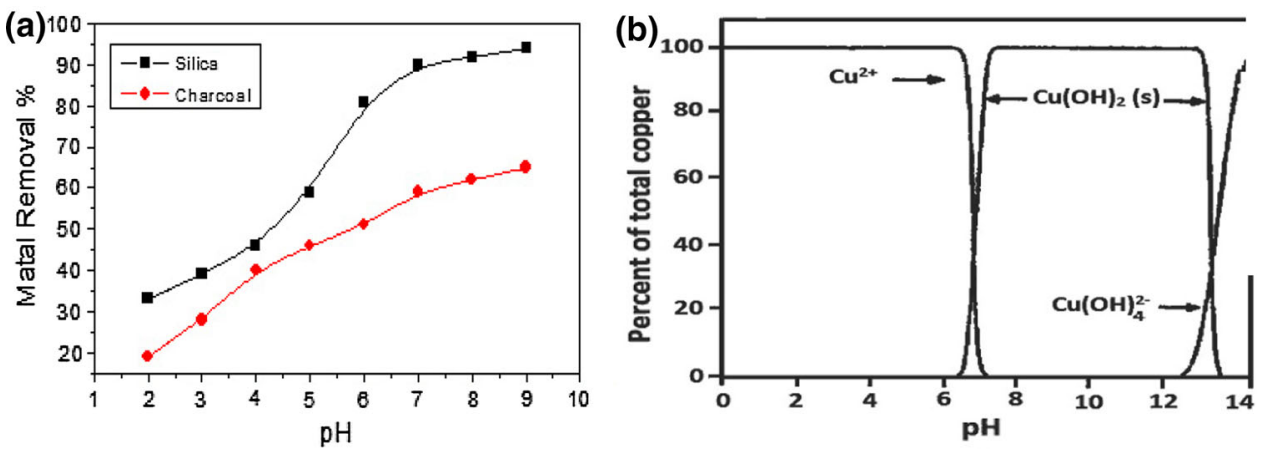

Fig. 3 Effect of $\mathrm{pH}$ on the amount of $\mathrm{Cu}^{2+}$ ions sorbed on both studied sorbents (a) and the speciation distribution diagram for copper (II)- $\mathrm{H}_{2} \mathrm{O}$ system at copper(II) concentration $=1.574 \times 10^{-4} \mathrm{M}(\mathbf{b})$ (Hoong and Ali 2000)

Also, the sorption of metal ions on hydrous oxide surface can probably be explained on the basis of the surface complex formation model. In this model, the hydrolysis of silicon dioxide produces hydrous oxide surface group $\mathrm{SiOH}$, i.e., the silanol group. This results in the formation of silica surface as weakly acidic. The cation exchange reaction can occur in aqueous solution as follows (Khalid et al. 1999):

$m-(\mathrm{SiOH}) \leftrightarrow m(\mathrm{SiO}-)+m \mathrm{H}^{+}$

$M^{n+}+m\left(-\mathrm{SiO}^{-}\right) \leftrightarrow M(\mathrm{OSi}-)_{m}^{n-m}$

The overall reaction can be represented as:

$M^{n+}+m(-\mathrm{SiOH}) \leftrightarrow M(\mathrm{Osi}-)_{m}^{n-m}+m \mathrm{H}^{+}$

where $M^{n+}$ is the metal ion with $n^{+}$charge, $-\mathrm{SiOH}$ is the silanol group on $\mathrm{SiO}_{2}$ surface, and $m \mathrm{H}^{+}$is the number of protons released.

The last reaction is reversible in acid solution. In the present study, the decrease in the sorption of copper at higher acidic medium can be explained on the basic of competitive reaction of the protons in the medium and positively charged copper(II) ions. While small sorption of metal at low $\mathrm{pH}$ is in accordance with the concept of zero point charge (pHzpc) which lies in the range of 1.8-2.2 for $\mathrm{SiO}_{2}$ (Khalid et al. 1999). Also the sample may contain other organic compounds in Si-sample which the sorption may be due to the electrostatic attraction with the surface groups.

It should be noted that at high $\mathrm{pH}$ values, sorption may not be the mechanism responsible for metal removal. It is clear from Fig. $3 b$ that substantial precipitation of $\mathrm{Cu}(\mathrm{OH})_{2}$ (s) occurs in the $\mathrm{pH}$ range of 7-13. According to Fig. 4, $95.5 \%$ of the total amount of copper(II) appears as precipitate at $\mathrm{pH} 7$.

\section{Effect of contact time}

Figure 4 shows, the plot of the amount of $\mathrm{Cu}^{2+}$ ions sorbed from aqueous solution onto prepared $\mathrm{SiO}_{2}$ and

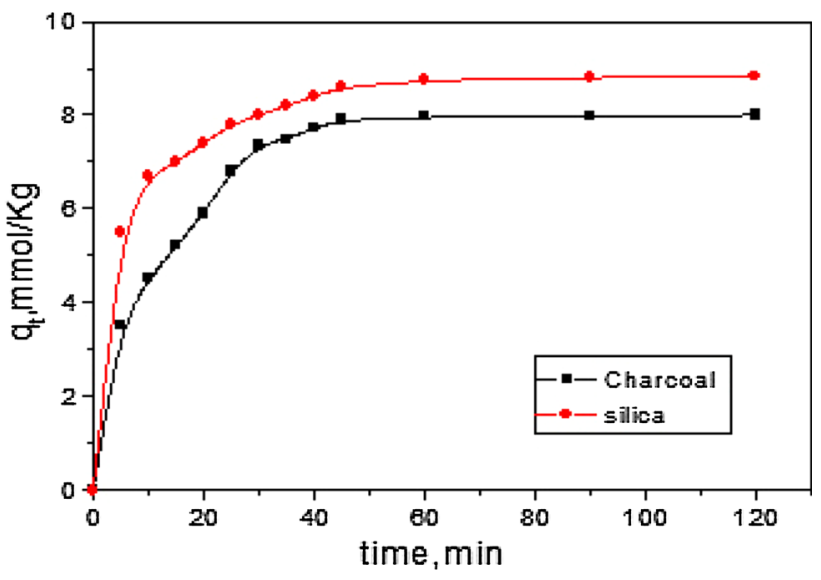

Fig. 4 Effect of contact time on the amount sorbed of $\mathrm{Cu}^{2+}$ ions on both studied sorbents

charcoal powder at room temperature $\left(25.0 \pm 0.1{ }^{\circ} \mathrm{C}\right)$ and $\mathrm{pH}=6.0 \pm 0.01$, as a function of contact time. The figure shows a high initial rate of removal within the first 40 min of contact (up to $80 \%$ removal) followed by a slower subsequent removal rate that gradually approached an equilibrium condition in about $1 \mathrm{~h}$. It should be noted that the diffusion of metal ions onto the sorbent lattice is a time dependent. Therefore, pseudo-equilibrium is attained when the contact time is lengthened. On the basis of these results, $2 \mathrm{~h}$ of equilibration time was chosen as the optimum period to ensure equilibrium conditions.

\section{Sorption kinetic models}

The dynamics of the sorption process in terms of the order and the rate constant can be evaluated using the kinetic sorption data. The process of $\mathrm{Cu}^{2+}$ removal from an aqueous phase by any adsorbent can be explained by using kinetic models and examining the rate-controlling mechanism of the sorption process such as chemical reaction, diffusion control and mass transfer. The kinetic parameters 
are useful in predicting the sorption rate which can be used as important information in designing and modeling of the sorption operation. In order to clarify the kinetic characteristics of sorption of $\mathrm{Cu}^{2+}$ ions onto alkali-leached $\mathrm{SiO}_{2}$ and charcoal, two well-known kinetic models, namely pseudo-first-order and pseudo-second-order kinetic models, were applied to evaluate the experimental data.

\section{Pseudo-first-order model}

The plot of $\log \left(q_{\mathrm{e}}-q_{t}\right)$ versus $t$ gives a straight line as shown in Fig. 5a which represents the pseudo-first-order kinetics for the removal of $\mathrm{Cu}^{2+}$ by the two investigated sorbents. The values of first-order rate constants, $k_{1}$ and $q_{e}$ for the initial $\mathrm{Cu}^{2+}$ concentration of $100 \mathrm{mg} \mathrm{l}^{-1}$, by keeping the adsorbent amount constant $(10 \mathrm{~g} / \mathrm{l})$, are calculated and listed in Table 1. The coefficient of determination $\left(R^{2}\right)$ is found to be in the range of $0.976,0.997$ which seems to be good and shows the applicability of pseudo-first-order kinetic model for the removal of $\mathrm{Cu}^{2+}$ using both studied sorbents. The experimental value of $q_{e}$ obtained from experiments for initial $\mathrm{Cu}^{2+}$ concentrations is $9.78,9.24 \mathrm{mmol} / \mathrm{g}$, which is not in agreement as expected with the pseudo-first-order model-predicted values as given in Table 2. So, it could suggest that, sorption of $\mathrm{Cu}^{2+}$ ions onto both sorbents are not as first-order reaction.

\section{Pseudo-second-order model}

As a result of the non-applicability of pseudo-first-order model, the kinetics for the sorption of $\mathrm{Cu}^{2+}$ on both sorbents was tested with the second-order kinetic model. The application of the second-order kinetics by plotting $t / q_{t}$ versus $t$ is as shown in Fig. 5b, yielded the second-order rate constant, $k_{2}$, estimated equilibrium capacity $q_{\mathrm{e}}$, and the coefficient of determination $\left(R^{2}\right)$ for the initial $\mathrm{Cu}^{2+}$ concentration $1.574 \mathrm{mmol} / \mathrm{l}$, which are reported in Table 2 .
The calculated $q_{e}$ values show a good agreement with the experimental values and the obtained values for coefficient of determination $\left(R^{2}\right)$ are more than 0.997 which indicates that the second-order kinetic model describes well the removal of $\mathrm{Cu}^{2+}$ using both adsorbents.

\section{Sorption isotherms}

Sorption isotherms are important to describe the sorption mechanism for the interaction of $\mathrm{Cu}^{2+}$ on the adsorbent surface. The equilibrium studies are useful to obtain the sorption capacity of both sorbents for $\mathrm{Cu}^{2+}$ removal. The sorption isotherm is characterized by certain constants that express the surface properties and the affinity of the adsorbent toward $\mathrm{Cu}^{2+}$. The equilibrium data for the sorption of $\mathrm{Cu}^{2+}$ using the studied sorbents fit into various isotherm models which results in a suitable model that can be used for the design of an sorption process. In the present study, Freundlich and Langmuir equilibrium models are analyzed to investigate the suitable sorption isotherm.

\section{Freundlich isotherm model}

A plot of $\log q_{e}$ versus $\log C_{e}$ yields straight lines. These linear plots support the applicability of the Freundlich sorption isotherm in the present study. It is valid for physical sorption and usually for as adsorbent with very heterogeneous surface (Benes and Majer 1980).

The values of $1 / n$ and $k_{f}$, which are rough measures of the sorption intensity and sorption capacity of the sorbent, respectively, have been determined by a least square fit program and were given in Table 3 . The values of $1 / n<1$, and it indicates favorable sorption of $\mathrm{Cu}(\mathrm{II})$ on both studied adsorbents. Similar results were reported by other workers for the sorption of Copper by rice husk and modified rice husk (Ong et al. 2007). The determination value of $1 / \mathrm{n}$ is of the same order of magnitude as those reported by other workers for various metal oxide adsorbents (Ye et al.
Fig. 5 Pseudo-first-order (a) and Pseudo-second-order (b) kinetic plots for sorption of $\mathrm{Cu}^{2+}$ ions on both studied sorbents
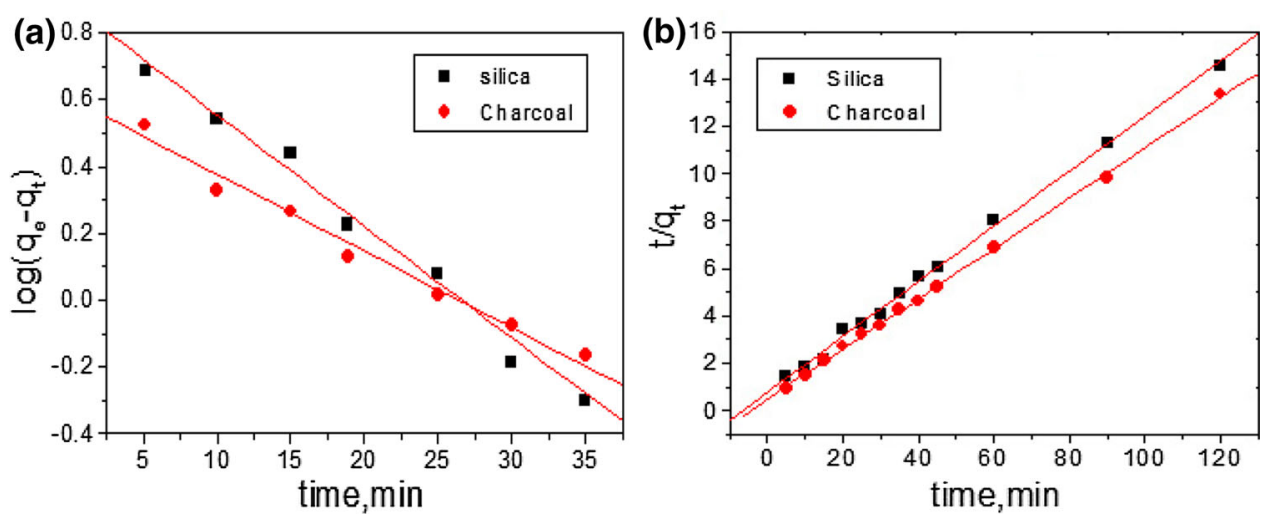
Table 2 Calculated parameters of the pseudo-first-order and pseudo-second-order kinetic models for $\mathrm{Cu}^{2+}$ ions sorbed onto $\mathrm{SiO}_{2}$ and charcoal

\begin{tabular}{|c|c|c|c|c|c|c|c|c|}
\hline \multirow[t]{2}{*}{ Sorbent type } & \multicolumn{3}{|c|}{ First-order kinetic parameters } & \multicolumn{4}{|c|}{ Second-order kinetic parameters } & \multirow[t]{2}{*}{$q_{e}(\exp \cdot \mathrm{mmol} / \mathrm{g}$} \\
\hline & $k_{1}\left(\min ^{-1}\right)$ & $q_{e}(\mathrm{calc} \mathrm{mmol} / \mathrm{g})$ & $R^{2}$ & $K_{2}(\mathrm{~g} / \mathrm{mmol} \mathrm{min})$ & $q_{e}(\mathrm{calc} \mathrm{mmol} / \mathrm{g}$ & $h(\mathrm{mmol} / \mathrm{g} \min )$ & $R^{2}$ & \\
\hline Alkali-leached $\mathrm{SiO}_{2}$ & 0.0677 & 7.50 & 0.976 & 0.0386 & 9.47 & 2.426 & 0.999 & 9.78 \\
\hline Charcoal & 0.0448 & 4.32 & 0.997 & 0.0278 & 8.93 & 1.362 & 0.998 & 9.24 \\
\hline
\end{tabular}

2012). The value of $1 / \mathrm{n}$ is usually related to the nature and strength of sorption forces. The higher fractional value of $1 / \mathrm{n}$ signifies that stronger sorption forces are operative on the surface of silica than activated charcoal. The higher value of $\mathrm{k}_{\mathrm{f}}$ further confirms the higher affinity of copper for silica rather than activated charcoal.

\section{Langmuir isotherm model}

The graphic presentations of $C_{e} / q_{e}$ versus $C_{e}$ give straight lines, which confirming that this expression is indeed a reasonable representation of chemisorption isotherm. The numerical value of constants $Q^{0}$ and $b$ evaluated from the slope and intercept of each plot is given in Table 3 . The value of saturation capacity $Q^{0}$ corresponds to the monolayer coverage and defines the total capacity of the clay for a specific metal ion. The Langmuir constants $Q^{0}$ and $b$ increased with temperature showing that the sorption capacity and intensity of sorption are enhanced at higher temperatures. Similar results have also been reported for sorption of copper by oyster shell powder (Hsu 2009). This increase in sorption capacity with temperature suggested that the active surfaces available for sorption have increased with temperature (El-Kamash et al. 2005). From data of sorption capacity, $\left(Q^{0}\right), t$ was shown that alkali-leached $\mathrm{SiO}_{2}$ is more favorable for sorption of $\mathrm{Cu}^{2+}$ ions than activated charcoal.

The Langmuir equation is also used to obtain $R_{L}$, the dimensionless equilibrium parameter or the separation factor (Hall et al. 1966; Juang et al. 1997) from the expression (Eq. 13):

$R_{L}=\left[1 /\left(1+b C_{o}\right)\right]$

where $C_{0}$ is the initial concentration of the adsorptive. For favorable sorption, $0<R_{L}<1$; while $R_{L}>1, R_{L}=1$ and
$R_{L}=0$, respectively, describe unfavorable, linear and irreversible sorption (Kadirvelu and Namasivayam 2003).

\section{Effect of temperature}

Temperature has two major effects on sorption processes. Increasing temperature is known to increase the rate of diffusion of the adsorbate molecules across the external boundary layer and in the internal pores of the adsorbent particle, owing to the decrease in velocity of the solution. In addition, changing the temperature will change the equilibrium capacity of the adsorbent for a particular adsorbate (Abd El-Rahman et al. 2006). In order to gain insight into the thermodynamic nature of the sorption process, several thermodynamic parameters for the present systems were calculated. The Gibbs free energy change, $\Delta G^{\mathrm{o}}$, is the fundamental criterion of spontaneously. Reactions occur spontaneously at a given temperature if $\Delta G^{\mathrm{o}}$ is a negative quantity. The free energy of the sorption reaction is given by the following Eq. (14):

$\Delta G^{\mathrm{o}}=-R T \ln K_{c}$

where $K_{c}$ is the sorption equilibrium constant, $R$ is the gas constant and $T$ is the absolute temperature $(K)$. The values of the thermodynamic equilibrium constant $\left(K_{c}\right)$ at different studied temperatures were determined from the product of the Langmuir equation parameters $Q^{0}$ and $b$ (Abd ElRahman et al. 2006). The variation of $K_{c}$ with temperature, as summarized in Table 4, showed that $K_{c}$ values increase with increase in sorption temperature, thus implying a strengthening of adsorbate-adsorbent interactions at higher temperature. Also, the obtained negative values of $\Delta G^{\mathrm{o}}$ confirm the feasibility of the process and the spontaneous nature of the sorption processes.

Table 3 Langmuir and Freundlich isotherm parameters for the sorption of $\mathrm{Cu}^{2+}$ on both studied sorbents at different temperature

\begin{tabular}{|c|c|c|c|c|c|c|c|c|}
\hline \multirow[t]{2}{*}{ Sorbent type } & \multirow[t]{2}{*}{ Temp $\left({ }^{\circ} \mathrm{C}\right)$} & \multicolumn{4}{|c|}{ Langmuir model parameters } & \multicolumn{3}{|c|}{ Freundlich model parameters } \\
\hline & & $Q^{0}(\mathrm{mmol} / \mathrm{g})$ & $b * 10^{-3}(1 / \mathrm{mmol})$ & $R^{2}$ & $R_{L}$ & $1 / n$ & $K_{f}(\mathrm{mmol} / \mathrm{g})$ & $R^{2}$ \\
\hline \multirow[t]{3}{*}{ Alkali-leached $\mathrm{SiO}_{2}$} & 25 & 213.3 & 27.74 & 0.997 & 0.258 & 0.857 & 13.50 & 0.999 \\
\hline & 40 & 222.5 & 53.02 & 0.996 & 0.161 & 0.786 & 18.87 & 0.997 \\
\hline & 60 & 242.5 & 166.56 & 0.984 & 0.054 & 0.632 & 23.67 & 0.998 \\
\hline \multirow[t]{3}{*}{ Activated charcoal } & 25 & 78.20 & 42.50 & 0.998 & 0.194 & 0.738 & 4.42 & 0.998 \\
\hline & 40 & 86.10 & 65.73 & 0.994 & 0.152 & 0.673 & 4.83 & 0.996 \\
\hline & 60 & 94.35 & 115.87 & 0.997 & 0.086 & 0.635 & 7.78 & 0.995 \\
\hline
\end{tabular}


Table 4 Thermodynamic parameters for sorption of $\mathrm{Cu}^{2+}$ ions on both studied sorbents

\begin{tabular}{|c|c|c|c|c|c|}
\hline Sorbent type & Temp $\left({ }^{\circ} \mathrm{C}\right)$ & $K_{c}$ & $-\Delta G^{\mathrm{o}}(\mathrm{kJ} / \mathrm{mol})$ & $\Delta H^{\mathrm{o}}(\mathrm{kJ} / \mathrm{mol})$ & $\Delta S^{\mathrm{o}}(\mathrm{kJ} / \mathrm{mol})$ \\
\hline \multirow[t]{4}{*}{ Alkali-leached $\mathrm{SiO}_{2}$} & 25 & 20.09 & 7.43 & \multirow[t]{4}{*}{24.44} & \multirow[t]{4}{*}{105.75} \\
\hline & 40 & 27.39 & 8.61 & & \\
\hline & 50 & 36.59 & 9.67 & & \\
\hline & 60 & 48.69 & 10.76 & & \\
\hline \multirow[t]{4}{*}{ Charcoal } & 25 & 16.44 & 6.94 & \multirow[t]{4}{*}{10.64} & \multirow[t]{4}{*}{58.99} \\
\hline & 40 & 20.44 & 7.85 & & \\
\hline & 50 & 23.33 & 8.46 & & \\
\hline & 60 & 25.42 & 8.96 & & \\
\hline
\end{tabular}

Fig. 6 Vant'Hoff plot of the sorption of copper on both studied sorbents
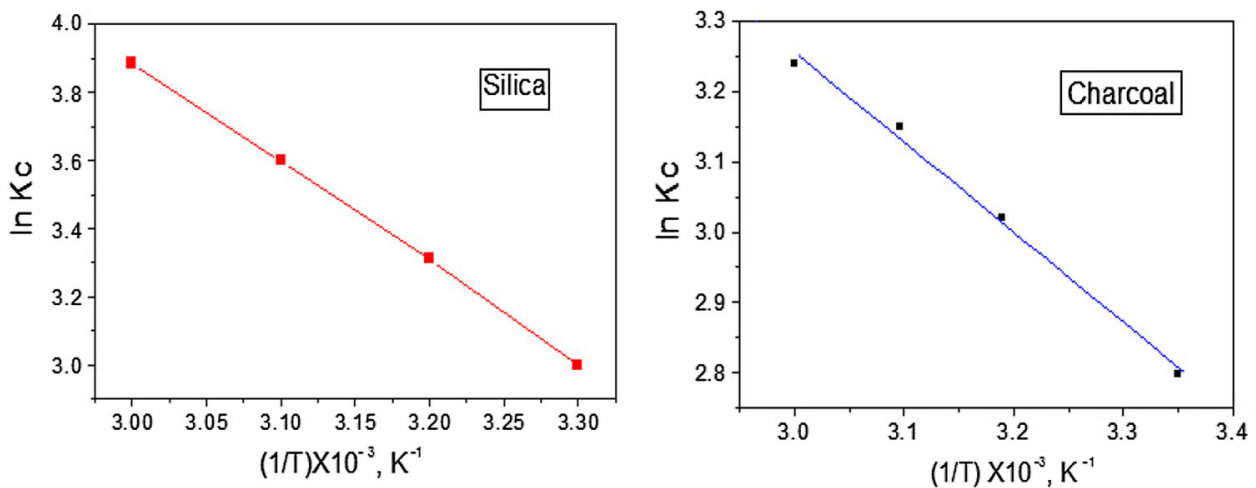

Other thermal parameters such as enthalpy change $\left(\Delta H^{\mathrm{o}}\right)$ and entropy change $\left(\Delta S^{\mathrm{o}}\right)$ were calculated using Vant'Hoff plot linear relationship (Eq. 15):

$\operatorname{Ln} K_{c}=\left(\Delta S^{o}\right) / R-\left(\left(\Delta H^{o}\right) / R T\right.$

The values of enthalpy change $\left(\Delta H^{\circ}\right)$ and entropy change $\left(\Delta S^{\circ}\right)$ calculated from the slope and intercept of the plot of $\ln$ $K_{c}$ versus $1 / T$ (Fig. 6) are also given in Table 4. The change in $\Delta H^{\mathrm{o}}$ was found to be positive confirming the endothermic nature of the sorption processes. $\Delta S^{\mathrm{o}}$ values were found to be positive due to the exchange of $\mathrm{Cu}^{2+}$ ions with more mobile ions present on the sorbents, which would cause increase in the entropy during the sorption process.

\section{Conclusion}

Alkali-leached silica and charcoal were tested as sorbent materials for the removal of copper ions from aqueous waste solution. The kinetics was experimentally studied and the obtained rate was analyzed using pseudo-first-order and pseudo-second-order kinetic models. Results suggest that the sorption of $\mathrm{Cu}$ (II) ions onto both studied sorbents followed the pseudo-second-order rate. Equilibrium isotherms have been determined and tested for different isotherm expression, and the sorption data were successfully modeled using Langmuir and Freundlich approaches. The sorption is an endothermic process and the result show both silica and charcoal sorbents can be faithfully employed for the removal of $\mathrm{Cu}(\mathrm{II})$ ions in a wide range of concentrations.

Acknowledgments The authors are grateful to Soil and Water department, Nuclear Research Center for atomic absorption spectroscopy measurements.

\section{References}

Abd El-Rahman KM, El-Kamash AM, El-Sourougy MR, AbdelMoniem NM (2006) Thermodynamic modeling for the removal of $\mathrm{Cs}^{+}, \mathrm{Sr}^{2+}, \mathrm{Ca}^{2+}$ and $\mathrm{Mg}^{2+}$ ions from aqueous waste solutions using zeolite A. J Radioanl Nucl Chem 268(2):221-230

Abou-Sekkina MM, Issa RM, Bastawisy AE, El-Helece WA (2010) Characterization and evaluation of thermodynamic parameters for Egyptian heap fired rice straw ash (RSA). Int J Chem 2(1):81-88

Arivoli S, Hema M, Barathiraja C (2008) Comparative study on metal ions adsorption on a low cost Carbonaceous adsorbent kinetic equilibrium and mechanistic studies. Iran J Environ Health Sci Eng 5(1):1-10

Bakker R, Keijsers E, Beek H (2009) Alternative concepts and technologies for beneficial utilisation of rice straw, Wageningen UR Food \& Biobased Research, Food \& Biobased Research number 1176

Benes P, Majer V (1980) Trace chemistry of aqueous solutions. Elsevier, Amsterdam, p 200

Bulteel D, Garcia-Diaz E, Vernet C, Zanni E (2002) Alkali-silica reaction: a method to quantify the reaction degree. Cem Concr Res 32(8):1199-1206

Cao J, Xiao G, Xu X, Shen D, Jin B (2013) Study on Carbonization of lignin by TG-FTIR and high temperature carbonization reactor. Fuel Process Tech 106:41-47 
Chatterji S, Thailow N, Berabe MA (eds) (2000) Proceeding of the 11th international conference on alkali-aggregate reaction in Concrete, Quebec, (Canada), pp 21-29

Comez-Serrano V, Pastor-Villigas J, Duran-Valle CJ, ValenzuelaCalahorro C (1996) Heat treatment of rockrose char in air. Effect on surface chemistry and porous texture. Carbon 34(4):533-538

Davis RJ, Liu Z (1997) Titania-silica: a model binary oxide catalyst system. Chem Mater 9(11):2311-2324

Davis JA, Volesky B, Vierra RSHF (2000) Sargassum seaweed as biosorbent for heavy metals. Water Res 34(17):4270-4278

Davis TA, Volesky B, Mucci A (2003) A review of the biochemistry of heavy metal biosorption by brown algae. Water Res 37(18): $43,11-4330$

Den classer LS, Kataoka N (1981) Proceedings of the 5th international conference on alkali-aggregate reaction, Cape Town (South Africa), National Building Research Institute of the CSIR, p 7

Dron R (1990) Thermodynamique de la réaction alcali-silice. Bulletin de liaison des Ponts et Chaussées 166:55-59

El-Kamash AM, Zaki AA, El Geleel MA (2005) Modeling batch kinetics and thermodynamics of zinc and cadmium ions removal from waste solutions using synthetic zeolite A. J Hazard Mater 127(1-3):211-220

Elwan MM, Attriss MS, Mahmoud AA, Salem AS (2006) Characterization of rice straw/ash and using in clay bricks. Processing of first scientific environmental conference. Zagazig University, pp 79-92

Gõksungur Y, Üren S, Güvenc U (2005) Biosorption of cadmium and lead ions by ethanol treated waste baker's yeast. Bioresour Technol 96(1):103-109

Hall KR, Eagleton LC, Acrivos A, Vermeulen T (1966) Pore- and solid-diffusion kinetics in fixed-bed adsorption under constantpattern conditions. Ind Eng Chem Fundam 5(2):212-223

Ho YS, McKay G, Wase DAJ, Foster CF (2000) Study of the sorption of divalent metal ions onto peat. Adsorpt Sci Technol 18(7): 639-650

Hoong ChuK, Ali HashimM (2000) Adsorption of copper(II) and EDTA-chelated copper(II) onto granular activated carbons. J Chem Technol Biotechnol 75(11):1054-1060

Hsu TC (2009) Experimental assessment of adsorption of $\mathrm{Cu}^{2+}$ and $\mathrm{Ni}^{2+}$ from aqueous solution by oyster shell powder. J Hazard Mater 171(1-3):995-1000

Juang RS, Wt FC, Tseng RL (1997) The ability of activated clay for the adsorption of dyes from aqueous solutions. J Environ Technol 18(5):525-531

Júnior LM, Macedo GR, Duarte ML, Silva EP (2003) Biosorption of cadmium using the fungus Aspergillus niger. Braz J Chem Eng 20(3): $1-17$

Kadirvelu K, Namasivayam C (2003) Activated carbon from coconut coirpith as metal adsorbent: adsorption of $\mathrm{Cd}(\mathrm{II})$ from aqueous solution. Adv Environ Res 7(2):471-478

Kalapathy U, Proctor A, Shultz J (2000) Silica xerogels from rice hull ash: structure, density and mechanical strength as affected by gelation $\mathrm{pH}$ and silica concentration. J Chem Technol Biotechnol 75(6):464-468

Kazemipour M, Ansari M, Tajrobehkar S, Majdzadeh M, Kermani HR (2008) Removal of lead, cadmium, zinc, and copper from industrial wastewater by carbon developed from walnut, azelnut, almond, pistachio shell, and apricot stone. J Hazard Mater 150(1):322-327

Kenawy IMM, Hafez MAH, El-said KhS (1994) Study of the thermal decomposition of cellulose-hyphan and its complexes with some transition and indium metal ions. $\mathrm{J}$ Therm Anal Calorim 42(6): 1143-1145

Khalid N, Rahman A, Ahmad S, Toheed A, Ahmed J (1999) Adsorption behavior of rice husk for the decontamination of chromium from industrial effluents. J Radioanal Nucl Chem 240(3):775-781

Kobya M, Demirbas E, Senturk E, Ince M (2005) Adsorption of heavy metal ions from aqueous solutions by activated carbon prepared from apricot stone. Bioresour Technol 96(13):1518-1521

Kurihara LA, Fujihara ST, Alfaya RVS, Gushikem Y, Alfaya AAS, DeCastro SC (2004) Copper (II) adsorbed on $\mathrm{SiO}_{2} / \mathrm{SnO}_{2}$ obtained by the sol-gel processing method: application as electrochemical sensor for ascorbic acid. J Colloid Interface Sci 274(2):579-586

Lagergren S (1898) Zurtheorie der Sogenannten Adsorption Geloster Stolle. Kungliga Svenska Vetenskapskapsaka demiens, handLingar 24:1-39

Liu Y, Chang X, Guo Y, Meng S (2006) Biosorption and preconcentration of lead and Cadmium on waste Chinese herb Pang Da Hai. J Hazard Mater 135(1-3):389-394

Lodeiro P, Cordero B, Barriada JL, Herrero R, Sastre de Vicente ME (2005) Biosorption of cadmium by biomass of brown marine macroalgae. Bioresour Technol 96(16):1796-1803

Madhava Rao M, Ramesh A, Purna Chandra Rao G, Seshaiah K (2006) Removal of coppe and cadmium from the aqueous solutions by activated carbon derived from Ceiba pentandra hulls. J Hazar Mater B 129:123-129

Ong SA, Lim PE, Seng CE (2007) Kinetics of adsorption of Cu (II) and Cd (II) from aqueous solution on rice husk and modified rice husk. Electron J Environ Agric Food Chem 6(2):1764-1774

Pastor-Villegas J, Valenzuela-Calahorro C, Bernalte-Garcia A, Gomez-Serrano V (1993) Characterization study of char and activated carbon prepared from raw and extracted rockrose. Carbon 31(7):1061-1069

Pilau EJ, Silva RGC, Jardim ICF, Augusto F (2008) Molecularly imprinted sol-gel for solid phase extraction of phenobarbital. J Braz Chem Soc 19(6):1136-1143

Pool AB (1992) Proceedings of the 9th international conference on alkali-aggregate reaction, London (England). Concr Soc Publ CS 104(1):782-789

Salvado IMM, Navarro JMF (1992) $\mathrm{TiO}_{2}-\mathrm{SiO}_{2}$ glasses prepared by the alkoxide route. J Non-Cryst Solids 147-148:256-261

Sharma P, Kumari P, Srivastava MM, Srivastava S (2006) Removal of cadmium from aqueous system by shelled moringa oleifera seed powder. Bioresour Technol 97(2):299-305

Silva G, Mattos EC, Dutra RC, Diniz MF, Iha K (2008) Quantitative determination of TNT and HNS by TG and FT-IR. Quim Nova 31(6):1431-1436

Solum MS, Pugmire RJ, Jagtoyen M, Derbyshire F (1995) Evolution of carbon structure in chemically activated wood. Carbon 33(9):1247-1254

Van Soest PJ (2006) Rice straw: the role of silica and treatments to improve quality. Anim Feed Sci Technol 130(4):137-171

Vasuderan P, Padmavathy V, Dhingra SC (2003) Kinetics of biosorption of cadmium on Baker's yeast. Bioresour Technol 89(3):281-287

Vink P, van der Eijk M, Verbree M, Voskamp AF, Van Bekkum H (1994) Modification of the surfaces of a gas activated carbon and a chemically activated carbon with nitric acid, hypochlorite, and ammonia. Carbon 32(4):675-686

Wang H, Gillott JE (1991) Mechanism of alkali-silica reaction and the significance of calcium hydroxide. Cem Concr Res 21(4):647-654

Ye H, Zhang L, Zhang B, Wu G, Du D (2012) Adsorptive removal of $\mathrm{Cu}(\mathrm{II})$ from aqueous solution using modified rice husk. Int J Eng Res Appl 2(2):855-863

Zaky RR, Hessien MM, El-Midany AA, Khedr MH (2008) Preparation of silica nanoparticles from semi-burned rice straw ash. Powder Technol 185(1):31-35 